\title{
Graphite nodule count and size distribution in thin-walled ductile cast iron
}

\author{
Pedersen, Karl Martin; Tiedje, Niels Skat
}

Published in:

Materials Characterization

Link to article, DOI:

10.1016/j.matchar.2007.09.001

Publication date:

2008

Link back to DTU Orbit

Citation (APA):

Pedersen, K. M., \& Tiedje, N. S. (2008). Graphite nodule count and size distribution in thin-walled ductile cast iron. Materials Characterization, 59(8), 1111-1121. https://doi.org/10.1016/j.matchar.2007.09.001

\section{General rights}

Copyright and moral rights for the publications made accessible in the public portal are retained by the authors and/or other copyright owners and it is a condition of accessing publications that users recognise and abide by the legal requirements associated with these rights.

- Users may download and print one copy of any publication from the public portal for the purpose of private study or research.

- You may not further distribute the material or use it for any profit-making activity or commercial gain

- You may freely distribute the URL identifying the publication in the public portal

If you believe that this document breaches copyright please contact us providing details, and we will remove access to the work immediately and investigate your claim 


\title{
Graphite nodule count and size distribution in thin- walled ductile cast iron
}

\author{
Karl Martin Pedersen and Niels S. Tiedje*
}

Department of Manufacturing Engineering and Management, Technical University of Denmark, Produktionstorvet, DK-2800 Kgs. Lyngby, Denmark

*Corresponding author, e-mail nt@ipl.dtu.dk. Phone: +45 4525 4719. Fax: +45 4593 4570.

Post-print of article in Materials Charaterization 59 (2008) 1111-1121

(Layout and minor sub-editing changes have been made to the published article)

Link to article: http://dx.doi.org/10.1016/j.matchar.2007.09.001

Link to journals homepage: www.elsevier.com/wps/product/cws_home/505786

\section{Abstract}

Graphite nodule count and size distribution have been analysed in thin walled ductile cast iron. The 2D nodule counts have been converted into 3D nodule count by using Finite Difference Method (FDM).

Particles having a diameter smaller than $5 \mu \mathrm{m}$ should be neglected in the nodule count as these are inclusions and micro porosities that do not influence the solidification morphology. If there are many small graphite nodules as in thin walled castings only 3D nodule count calculated by FDM will give reliable results. 2D nodule count and 3D nodule count calculated by simple equations will give too low results.

The 3D size distribution showed presence of primary graphite nodules in hypereutectic castings.

In thin plates the nodule count is similar in eutectic and hypereutectic plates. In thicker plates the hypereutectic casting has the highest nodule count.

\section{Keywords}

Ductile cast iron; Thin walled castings; Graphite nodules; 2D to 3D nodule count; Solidification

\section{Introduction}

Thin walled ductile cast iron has good mechanical properties and is more economical in production compared with many other materials. By geometrical optimisation of the 
casting it can be favourable to replace traditionally light materials with thin walled ductile cast iron.

The microstructure of ductile cast iron is characterised by the presence of spherical graphite particles or nodules throughout the material. These graphite nodules are nucleated on small inclusions during the solidification [1]. During the eutectic solidification the graphite nodules will be surrounded by austenite and growth of the graphite nodules will then occur by diffusion of carbon from the liquid through the austenite shell [2].

The graphite nodule count and size distribution are very important for the properties of the final material. First of all a sufficient number of graphite nodules is required in order to avoid formation of carbides during solidification, especially in thin walled castings because of the high solidification rate. The presence of carbides in the microstructure will have a detrimental effect on the mechanical properties.

The number of graphite nodules will influence the ferrite/pearlite content of the matrix and by that the mechanical properties. The nodule count and nodule diameter will also have an influence on fatigue strength $[3,4]$

The graphite nodule count is therefore an important parameter in the characterisation of the microstructure of ductile cast iron.

The characterisation of graphite nodules in ductile cast iron is normally done by visual comparison of polished, unetched cross sections with standard charts (e.g. ISO 945) or by using digital microstructure analysis.

Using digital analysis the magnification or more correct the pixel size of the images for this analysis is important. Ruxanda et al. [5] have analysed the use of pixel size and found that a pixel size of around $0.53 \mu \mathrm{m}$ was a good optimum between the resolution of the graphite nodules and the number of metallographic fields to be analysed to get a reasonable analysed area. This is in good agreement with what has been used in other works: $0.45 \mu \mathrm{m}$ in [6] and $0.59 \mu \mathrm{m}$ in [7].

A related problem to the pixel size is the minimum size of the graphite nodules before it is included in the nodule count. In order to get a reasonable resolution of the shape of the graphite nodules Ruxanda et al. [5] recommends a minimum diameter of 5 $\mu \mathrm{m}$. This will give an increasing nodule count with decreasing plate thickness. A minimum diameter of $10 \mu \mathrm{m}$ will give a decreasing nodule count with decreasing plate thickness, which is unlikely. Other criteria to determine the minimum nodule size used in the literature are: a minimum perimeter of $5 \mu \mathrm{m}$ (corresponds to a circle with diameter of $1.59 \mu \mathrm{m}$ ) [7], a minimum area of $8 \mu \mathrm{m}^{2}$ (corresponds to a circle with diameter of $3.19 \mu \mathrm{m}$ ) for plates thinner than $10 \mathrm{~mm}$ [8] or a minimum area of $30 \mu^{2}$ (corresponds to a circle with diameter of $6.2 \mu \mathrm{m}$ ) [9]. Lacaze et al. have found that both 
the area and the volume nodule size distribution are bimodal with a minimum corresponding to a diameter of 7 to $10 \mu \mathrm{m}$ [10]. Particles below this minimum were neglected in the nodule count as these could be porosities and inclusions instead of graphite nodules and because the graphite fraction related to the small nodules is small anyway [10]. In some cases there have not been reported a minimum limit but it seems that all detectable particles have been incorporated in the nodule count, see e.g. [6, 11].

The computerised nodule count will be a 2D area count. The graphite nodule will however be dispersed through the volume of the casting, as 3D. It is therefore useful to convert the 2D count into 3D count. Assuming a volume count $N_{\mathrm{V}}$ of spherical graphite nodules with diameter $d$ the number of graphite nodules that intersect a surface, $N_{\mathrm{A}}$, will be:

$$
N_{\mathrm{A}}=d \cdot N_{\mathrm{V}}
$$

The mean graphite diameter can be calculated by:

$$
d=\left(\frac{6 f^{\mathrm{g}}}{\pi N_{\mathrm{V}}}\right)^{1 / 3}
$$

where $f^{g}$ is the fraction of graphite. Combining Eqs. (1) and (2) will give:

$$
N_{\mathrm{V}}=\left(\frac{\pi}{6 f^{\mathrm{g}}}\right)^{1 / 2}\left(N_{\mathrm{A}}\right)^{3 / 2}
$$

Normally the fraction of graphite will be around 0.1 and Eq. (3) can then be simplified to $N_{\mathrm{V}}=2.29\left(N_{\mathrm{A}}\right)^{3 / 2}$. Eq. (3) is based on that all graphite nodules have the same size. Normally there will be some variation of the sizes. Owadano et al. has therefore the relationship [12]:

$$
N_{\mathrm{V}}=\left(\frac{\pi}{6 f^{\mathrm{g}}}\right)^{1 / 2}\left(\alpha N_{\mathrm{A}}\right)^{3 / 2}
$$

where $\alpha$ is a parameter between 1 and 1.25, depending on the width of the size distribution of the graphite nodules. If all the graphite nodules have the same size $\alpha$ will be equal to 1 . A normal value of $\alpha$ is around 1.2 [13].

Charbon has based on stochastic modelling of solidification of ductile cast iron found the dependency [14]:

$$
N_{\mathrm{V}}=2.83\left(N_{\mathrm{A}}\right)^{3 / 2}
$$

This is however based on the fraction of graphite just after the end of the solidification process and not after cooling to room temperature. According to [15] the fraction of graphite will increase from about 0.07 after the solidification to about 0.1 after cooling to room temperature. Taking that into account Eq. (5) will be changed to 
$N_{\mathrm{V}}=2.37\left(N_{\mathrm{A}}\right)^{3 / 2}$, which corresponds to $\alpha \approx 1.02$ in Eq. (4). Based on the tempered graphite particles in malleable cast iron Saltykov has found the relation, which is in good agreement with the previous equations [16]:

$$
N_{\mathrm{V}}=2.38\left(N_{\mathrm{A}}\right)^{1.6}
$$

In contrast to the previous equations Eq. (6) is only valid if $N_{\mathrm{A}}$ is in the unit $\mathrm{mm}^{-2}$ and $N_{\mathrm{V}}$ is in $\mathrm{mm}^{-3}$.

All the above equations are based on some sort of standard size distribution. In order to account for different nodule size distribution the Schwartz-Saltykov method (also called Saltykov method) can be used [17]. Here the 2D size distribution is divided into $k$ class intervals of size $\Delta$ ( $k$ should preferably be at least 7$)$. $\left(N_{\mathrm{A}}\right)_{i}$ is the number of particles per unit area in the size interval $(i-1) \Delta$ to $i \Delta$, where $i$ varies from 1 to $k$. The number of particles per unit volume, $\left(N_{\mathrm{V}}\right)_{j}$ having size $j \Delta$ (where $j$ varies from 1 to $k$ ) is calculated by [17]:

$$
\left(N_{\mathrm{V}}\right)_{j}=\frac{1}{\Delta} \sum_{i=j}^{k} \alpha(i, j)\left(N_{\mathrm{A}}\right)_{i}
$$

The coefficients $\alpha(i, j)$ are tabulated for $k \leq 15$ in [17], but $\alpha(i, j)$ can be calculated for $\mathrm{k}>15$ if it is required.

Basak and Sengupta [6] have developed a finite difference method (FDM) which can be used in similar way as the Schwartz-Saltykov method. However they assume that $\left(N_{\mathrm{V}}\right)_{j}$ has a continuous size distribution between $(j-1) \Delta$ to $j \Delta$ instead of just $j \Delta$ as in the Schwartz-Saltykov method. This will give some different coefficients $\alpha(i, j)$, which can be calculated by [6]:

$$
\begin{aligned}
& \alpha(i, i)=1 \quad \text { for } i=1 \\
& \alpha(i, i)=\frac{2}{\pi} \ln \left(\frac{i+\sqrt{i^{2}-(i-1)^{2}}}{i-1}\right) \quad \forall i>1 \\
& \alpha(i, j)=\frac{2}{\pi} \ln \left(\frac{i+\sqrt{i^{2}-(j-1)^{2}}}{i+\sqrt{i^{2}-j^{2}}} \times \frac{i-1+\sqrt{(i-1)^{2}-j^{2}}}{i-1+\sqrt{(i-1)^{2}-(j-1)^{2}}}\right) \quad \forall i>j
\end{aligned}
$$

As a continuous size distribution is more realistic than a discrete size distribution it can be assumed that the FDM by Basak and Sengupta is more accurate than the Schwartz-Saltykov method.

The aim of this work is to investigate how to the nodule count in thin walled castings is properly determined, whether $2 \mathrm{D}$ or $3 \mathrm{D}$ counts can be used and what the minimum size limit should be if it should be used. Finally there will a discussion of the influence of nodule count and size distribution on the solidification process. 


\section{Experimental procedure}

Castings were produced from hypereutectic and eutectic melts in batches of $90 \mathrm{~kg}$. The chemical analyses of the different casting experiments are shown in Table 1 . The melt was superheated to $1520^{\circ} \mathrm{C}$ before being poured into a preheated ladle for magnesium treatment with a Fe-Si-Mg alloy using a tundish sandwich method. The melt for each mould was then poured into a small insulated fibre cup where it was inoculated with $0.1-0.2 \%$ Fe-Si alloy before it was poured into the mould. The temperature was measured in the fibre cup with an S-type thermocouple and the casting temperature is shown in Table 1.

Two different casting layouts were used in the experiments. Casting layout A (Fig. 1a) consists of two parallel stepped plates with thicknesses of 8, 4.3 and $2.8 \mathrm{~mm}$. This layout was horizontally parted and the moulds were made of sodium silicate chemically bonded sand. Casting layout B (Fig. 1b) consists of 4 plates with thicknesses of 1.5, 2, 3 and $4 \mathrm{~mm}$. This layout was vertically parted and the moulds were made of green sand on a Disamatic Moulding Machine. In Table 2 is shown which casting layouts that have been used in the different experiments.

Characterization of graphite morphology and matrix microstructure was performed in the centre of cross sections of the plates close to the thermocouples. Areas with macroshrinkage porosities (identified by having an irregular shape [18]) were not used for analyses of microstructure. The micrographs were taken at a magnification of X156 which gave a pixel size of $0.57 \mu \mathrm{m}$. For each plate a total area of $4.8 \mathrm{~mm}^{2}$ was analysed. In all cases at least 1000 particles were measured. The size of particles was measured using the image tool Image-Pro Plus version 4.1. The two dimensional spatial size distribution of nodules was converted to a three dimensional size distribution by using a finite difference method developed by Basak and Sengupta [6]. A size interval, $\Delta$, of 2.5 $\mu \mathrm{m}$ was used for all plate thicknesses. This gave a reasonable resolution of the size distribution still having a high enough number of particles in each interval to give a smooth size distribution. The samples were etched in a nital solution to reveal ferrite, pearlite and carbides.

\section{Results}

\subsection{Particle size distribution in the plates}

Examples of microstructure in the 4 and $1.5 \mathrm{~mm}$ plates are shown in Fig. 2 for a hypereutectic and a eutectic casting. The size of the graphite nodules seem to be more uniform in the eutectic castings than in the hypereutectic castings. This effect was similar for the other plate thicknesses. 
Examples of 3-D nodule size distribution for hypereutectic and eutectic castings are shown in Figs. 3 and 4 for the 1.5, 2, 3 and 4 mm plates and Fig. 5 for the $8 \mathrm{~mm}$ plates. It can be seen that in the different castings the 3-D size distribution consists of different size distributions. In order to clarify this, curves of Normal distribution $\mathrm{N}\left(\mu, \sigma^{2}\right)$ or Logarithmic Normal distribution $\operatorname{LN}\left(\alpha, \beta^{2}\right)$ have been drawn on the graphs together with a curve of the sum of the different size distributions. The group of the smallest particles is approximated by a Logarithmic Normal distribution while the other groups are approximated by Normal distributions.

For the plate thickness $\leq 4.3 \mathrm{~mm}$ the sum of two or three different size distributions gave a very good fit with the actual size distributions, Figs. 3 and 4 . For the $8 \mathrm{~mm}$ plates there seems to be up to four different size distributions, Fig. 5. Due to fewer graphite nodules in the $8 \mathrm{~mm}$ plates there are larger scatter in the size distributions so the fit was not as good for the $8 \mathrm{~mm}$ plates as for the thinner plates.

The total number of particles is shown in Fig. 6. There is a large scatter in the number of particles, probably because of scatter in the count of the small particles due to the resolution of the microstructure micrographs [19]. The total number of particles is similar for the 8 and $4.3 \mathrm{~mm}$ plates but for plates thinner than $4.3 \mathrm{~mm}$ the number of particles is increasing with decreasing plate thickness.

\subsubsection{Small particles}

In all castings there was a group of small particles, the main part of them having a size between 0 to $5 \mu \mathrm{m}$, with an average of around $3 \mu \mathrm{m}$, see Figs. $3-5$. This may be small inclusions of magnesium sulphides and oxides from the nodulizing and inoculation treatment of the melt [1]. The average size of this type of inclusions has previously been found to be around 1.5 to $2.0 \mu \mathrm{m}$ [1]. These types of inclusions can act as nucleation particles for graphite [1] and graphite may also have precipitated on some of the inclusions during the last part of the solidification or during the cooling to the room temperature [20, 21].

Some of the inclusions can also be magnesium phosphide [1]. These inclusions will be located at the grain boundaries and are not acting as nucleation particles.

Finally what seem to be small particles can also be micro-shrinkage or porosities. According to Stefanescu et al. [18] micro-shrinkage is normally formed in ductile cast iron at the grain boundaries at the end of the solidification.

At high magnification some of the small particles have an irregular shape indicating that these could be either particles of magnesium phosphide [1] or interdentritic microshrinkage [18]. Others are more circular as magnesium oxides and sulphides [1]. 


\subsubsection{Limit between inclusions/porosities and graphite nodules}

The larger particles (larger than 5 to $10 \mu \mathrm{m}$ ) are all supposed to be graphite nodules. The size limit between the inclusions/porosities and the graphite nodules is based on the fitted curve for the individual groups as shown in Figs. 3-5. The average of the used size limit is shown in Fig. 7 as a function of the plate thickness. Except for the $1.5 \mathrm{~mm}$ plates the size limit is in between 7 and $10 \mu \mathrm{m}$ (as in [10]) with an increasing size limit for increasing plate thickness. The $1.5 \mathrm{~mm}$ plates seem to have a lower limit of only 5 $\mu \mathrm{m}$. The reason that the size limit increases with increasing plate thickness is that there will be some diffusion of carbon to the small inclusions after termination of solidification during the cooling to room temperature [21]. The smaller the cooling rate is the larger the precipitation will be.

The limit size for the eutectic is a little higher than for the hypereutectic castings. This is probably because the average size of the graphite nodules is larger for the eutectic casting than for the hypereutectic castings.

\subsubsection{Graphite nodules}

The average nodule count for the different plate thicknesses are shown in Fig. 8. The error bars are $95 \%$ confidence interval. The nodule count is similar for the hypereutectic and eutectic castings, except for the $8 \mathrm{~mm}$ plates where the hypereutectic casting has a higher nodule count. The tendency of similar nodule count in eutectic and hypereutectic castings is also seen in e.g. [8].

For plate thickness $\leq 4.3 \mathrm{~mm}$ there is one main group of graphite nodules and another group with fewer but larger nodules, Figs. 3 and 4 . The number of large nodules is shown in Fig. 9. The eutectic castings have only very few large nodules, typically around 100 nodules $\cdot \mathrm{mm}^{-3}$, and they are hardly visible on the figure with nodule size distributions, Fig. 4 . The hypereutectic castings have a higher number of large nodules and they are clearly visible in the nodule size distributions, Fig. 3.

In the $8 \mathrm{~mm}$ plates there are up to three different groups of graphite nodules, Fig. 5. There is a group of few but large nodules as in the thinner plates. The remaining nodules are divided in two groups. About one third of nodules are small, having a size of 10 to $15 \mu \mathrm{m}$. Finally, the third group of nodules has a size between the group of small nodules and the group of large nodules. This third group of nodules has also a larger variation in size distribution than the other groups. 


\section{Discussion}

\subsection{Nucleation and growth}

In ductile cast iron the graphite nodules are nucleated on small inclusions of magnesium oxides and sulphides [1]. After a graphite nodule has been nucleated on an inclusion it will start to grow by diffusion of carbon from the melt to the surface of the graphite nodule. At some point the graphite nodule will be surrounded by an austenite shell and further growth will occur by diffusion of carbon through the austenite shell [2]. As the diffusion of carbon is lower in austenite than in liquid the growth rate of the nodule will gradually decrease. Furthermore, during the eutectic growth the thickness of the austenite shell will increase as well which will further slow down the growth rate of the graphite nodules [22]. According to [2] new graphite nodules will be nucleated during the solidification. But as the growth rate is high for the small graphite nodules there will be very few small graphite nodules at the end of the solidification. Hence there is very few particles having a size between 5 and $10 \mu \mathrm{m}$, except for the $1.5 \mathrm{~mm}$ plates, see Figs. $3-5$. In case of the $1.5 \mathrm{~mm}$ plate the solidification is so fast that the average graphite nodule diameter is just below $10 \mu \mathrm{m}$, see Figs. 3 and 4.

\subsubsection{Large graphite nodules}

In the hypereutectic castings primary graphite nodules will nucleate some time before eutectic austenite + graphite, giving a group of primary graphite nodules, Fig. 9. The growth of the primary graphite nodules will not be inhibited by an austenite shell during the primary growth and they can therefore become larger than the main group of the graphite nodules. The group of large nodules in the hypereutectic castings is therefore associated with the primary graphite nodules. The number of primary graphite nodules is increasing from about 1300 nodules $\cdot \mathrm{mm}^{-3}$ in the $8 \mathrm{~mm}$ plates to about 4500 in the $1.5 \mathrm{~mm}$ plate, see Fig. 9. As the growth is controlled by diffusion a higher cooling rate will require a higher number of primary graphite nodules in order to maintain a sufficient equilibrium according to the phase diagram.

The number of primary graphite nodules is rarely treated in the literature. They have probably been present but they are not distinguishable in nodule counts.

Based on experimental data Bradley has made some calculation of the growth of primary graphite nodules [23]. The number of primary graphite nodules was set to 540 nodules $\mathrm{mm}^{-3}$, based on the number of nodules with a diameter between $35 \mu \mathrm{m}$ and 62 $\mu \mathrm{m}$, where the latter was the diameter of the largest nodule in the casting. As the experiment in [23] had a lower cooling rate than the $8 \mathrm{~mm}$ plate in the present work there is good agreement between the two sets of experiments. 
There were also large nodules present in some of the eutectic castings, but only about 100 large nodules $\cdot \mathrm{mm}^{-3}$, significantly lower than in the hypereutectic casting. The presence of large nodules in the eutectic castings can be due to special nucleation and growth conditions for some of the graphite nodules.

\subsubsection{Nodule size distribution and shrinkage}

Austenite will contract during solidification but in cast iron this will be compensated by the expansion of graphite. It is especially important that there is sufficient graphite expansion in the last part of the solidification when feeding from an external feeder normally is impossible [24]. Sufficient graphite expansion in the last part of solidification is identified by nucleation of graphite nodules in the last part of solidification, giving many small graphite nodules in the microstructure [25].

In the present castings the size of the main group of graphite nodules was very uniform for the plates with thickness $\leq 4.3 \mathrm{~mm}$, giving a normal size distribution; see Figs. 3 and 4 . This indicates that graphite nodules have not been nucleated in the last part of the solidification.

In the $8 \mathrm{~mm}$ plates the main part of the graphite nodules were divided into two groups, with a group of small graphite nodules having a size of about 10 to $15 \mu \mathrm{m}$, Fig. 5. These have probably been nucleated in the last part of the solidification and by that prohibit shrinkage.

In the present castings were there only few shrinkage porosities in the $8 \mathrm{~mm}$ plates but more shrinkage in the thinner plates. This corresponds to that the $8 \mathrm{~mm}$ plates have a group of small graphite nodules but not the thinner plates. However because the geometry can have an influence on generation of shrinkage porosities, the amount of porosities have not been quantified.

The presence of large primary nodules will also promote shrinkage porosities [26]. In the present castings $72 \%$ of the hypereutectic plates had shrinkage porosities while only $39 \%$ of the eutectic plates had that. Hypereutectic castings contain more carbon than the eutectic (see Table 1) so more carbon is available for graphite expansion. However due to precipitation of primary graphite nodules this graphite expansion occurs at the wrong time and shrinkage porosities are created.

\subsection{The total number of particles}

The total number of particles is decreasing with increasing plate thicknesses as shown in Fig. 6. Several factors can explain this effect. The number of magnesium sulphide and oxide inclusions will decrease with increasing plate thicknesses (and by 
that increasing solidification time) due to Ostwald ripening. The number of this type of inclusions will fade by [1]:

$$
N_{\mathrm{V}, \text { inclusions }}=\frac{n}{1.33+0.64 \cdot t / 60}
$$

where $n$ is a constant and $t$ is time in seconds after inoculation. Based on temperature measurement the time between inoculation and the end of solidification can be approximated by

$$
t=0.61 \cdot x^{2}+7.8 \cdot x
$$

where $x$ is the plate thickness in mm. This will, for the present interval of plate thicknesses, give an almost linear fading as a function of plate thicknesses, see Fig. 6. The number of magnesium sulphide and oxide inclusions (including the number of graphite nodules which are nucleated on these inclusions) will decrease with increasing plate thickness just as the total number of particles is decreasing. It seems however that other factors also affect the number of particles.

The number of micro porosities will increase with the number of graphite nodules due to the increasing areas of grain boundaries [18]. Increasing plate thicknesses will decrease the nodule count and by that decrease the number of micro porosities.

The change in cooling rates may also affect the number of magnesium phosphide inclusions.

\subsection{Influence of the small particles on the solidification}

As mentioned in the Introduction different minimum sizes of particles have been used as the lower limit for the nodule count in the literature. But before setting the minimum limit it should be determined whether the small inclusions have an influence on the solidification aside from acting as nucleation particles for the graphite nodules.

In order to evaluate which particles influence the solidification it will be beneficial to look at particles in the ferritic areas. After the casting has solidified, carbon will continue to diffuse from the austenite to the graphite nodules as the solubility of carbon in austenite decreases during cooling. During this stage the amount of graphite will increase from about 7 to $10 \mathrm{Vol}$ pct. [15]. When the eutectoid temperature is reached the areas close to the graphite nodules with the low content of carbon will be transformed to ferrite while the areas far away from the nodules will have a higher content of carbon so that pearlite forms. Hence, the graphite nodules will be located in ferritic areas and nongraphite particles may be expected to be randomly distributed.

For one sample from each casting $\mathrm{H} 4$ and $\mathrm{J} 4$, both $4 \mathrm{~mm}$ plates, the number of particles in the ferritic areas have been analysed on etched samples and compared with the results from the as polished samples. The $4 \mathrm{~mm}$ plate in casting $\mathrm{H} 4$ had $47 \%$ pearlite 
and casting J4 had 37\% pearlite. The results are shown in Fig. 10. For the particles with a size above $5 \mu \mathrm{m}$ the number of particles in each size interval is similar. For the particles having a size smaller than $5 \mu \mathrm{m}$ the number of particles in the ferritic areas is reduced with 60 to $70 \%$ in comparison to the as polished samples. If there had been diffusion of carbon to the small particles it could be expected that the majority of the small particles were placed in the ferritic areas. If the small particles were randomly placed in the casting the number of small particles should only have been reduced with what corresponds to the amount of pearlitic areas. It however seems that a majority of the small particles are placed at the grain boundaries. This indicates that at least some of the small particles are magnesium phosphides or micro porosities [1, 18].

Based on the ferritic/pearlite areas the particles having a diameter less than $5 \mu \mathrm{m}$ do not have an influence on the solidification process and they should therefore be excluded from the nodule count. The effect of not excluding the small particles can be seen in e.g. [7], where a minimum size limit corresponding to a circle with a diameter of $1.59 \mu \mathrm{m}$ was used. Here the nodule count (only given as area or 2D count) for the different plate thicknesses between 2 and $7 \mathrm{~mm}$ is very similar, only with a slight increase in the nodule count for decreasing plate thicknesses. The typical nodule count was in between 1000 to 2500 particles $\cdot \mathrm{mm}^{-2}$. Using Eq. (3), assuming $f^{\mathrm{g}}=0.1$, it corresponds to a volume count of 72,000 to 286,000 particles $\cdot \mathrm{mm}^{-3}$; about the same range as the total particle count in the present work, see Fig. 6.

In the present work it has been evaluated in each casting and plate thicknesses what the minimum size limit should be for the nodule count, see Fig. 7. In order to simplify the procedure a fixed minimum size limit could be used. The effects of using a minimum size limit of 5 or $10 \mu \mathrm{m}$ are shown in Fig. 11. For all plate thicknesses except the $1.5 \mathrm{~mm}$ plates the effect will be relatively small. A minimum size limit of $5 \mu \mathrm{m}$ will increase the nodule count a little (typically 5,000 to 10,000 nodules $\cdot \mathrm{mm}^{-3}$ ) while the limit of $10 \mu \mathrm{m}$ will decrease it a little (typically less than 5,000 nodules $\cdot \mathrm{mm}^{-3}$ ). This is because the number of particles in the range from 5 to $10 \mu \mathrm{m}$ is relatively small, see Figs. 3-5. However for the $1.5 \mathrm{~mm}$ plate the main part of the graphite nodules has a size in between 5 to $10 \mu \mathrm{m}$, see Figs. 3 and 4. Having a size limit of $10 \mu \mathrm{m}$ will therefore give a large decrease in the nodule count for the $1.5 \mathrm{~mm}$ plates, see Fig. 11. If a fixed minimum size limit has to be used a minimum size limit of $5 \mu \mathrm{m}$ will be reasonable. The same limit was also proposed by Ruxanda et al. [5] although this was due to an optimisation of the use of magnification vs. area viewed per micrograph and still having an increasing nodule count for decreasing plate thicknesses. 


\subsection{Area (2D) vs. volume (3D) nodule count}

When analysing the microstructure of ductile cast iron the easiest would be to use the area or 2D count. This is useful for microscope analysis but for comparison with numerical models a volume or 3D count will be more useful. Furthermore, combining thin walled casting with many small graphite nodules and a minimum size limit for the nodule count in order to eliminate the small inclusions and micro porosities, there are some problems related to use of 2D nodule count.

Having a planar cut through a spherical graphite nodule the visible diameter of the graphite will be a function of where the cut is placed in relation to the distance from the centre of the graphite nodule. Having a graphite nodule with diameter $d$ and a minimum size limit $d_{\text {limit }}$ the probability $p$ that the visible diameter will be small than $d_{\text {limit }}$ will be:

$$
p=1-\frac{\sqrt{d^{2}-d_{\text {limit }}^{2}}}{d} \quad d \geq d_{\text {limit }}
$$

In case of $d_{\text {limit }}=5 \mu \mathrm{m}$ the result of Eq. (11) is shown in Fig. 12. Having graphite nodules with a diameter of $6 \mu \mathrm{m} 45 \%$ of the graphite nodules will have a visible diameter less than $d_{\text {limit }}$, for a diameter $10 \mu \mathrm{m}$ it will be $13 \%$ and for a diameter of 20 $\mu \mathrm{m}$ it will be only $3 \%$. For castings with high nodule count the diameter of the graphite nodules will be small due to the total amount of graphite is relatively constant. The practical implication of using a 2D nodule count is that for castings with many small graphite nodules a higher fraction of the nodules will be neglected in the nodule count than for castings with few small graphite nodules. This will make it difficult to compare the results between thin walled and heavy sections. Further more this error will also affect the 3D nodule count if the nodule count is converted from 2D to 3D using simple methods as e.g. Eqs. (3) to (6).

The problem of the visible diameter of the graphite nodule can however be avoided by using the more advanced methods such as the Schwartz-Saltykov method [17] or the FDM developed by Basak and Sengupta [6]. In these methods the 3D nodule count larger than $d_{\text {limit }}$ will only be affected by the 2D nodule count larger than the same limit, see Eq. (7). The only necessary condition is that the $d_{\text {limit }}$ has to be an integral multiple of the size interval, $\Delta$.

In Fig. 13 the result of the FDM is compared with Eq. (4) taking into account the fraction of graphite. The Eq. (4) is based on the 2D nodule count with $d_{\text {limit }}=5 \mu \mathrm{m}$ while the 3D nodule count by the FDM has its $d_{\text {limit }}$ at the local minimum of the size distribution, see Figs. $3-5$ and 7. $\alpha=1.276$ gave the best fit between the two methods. The two methods gave very similar results except in three cases marked by * in Fig. 13. Compared with the remaining of the castings these three cases are characterised by that 
they have very few graphite nodules with a diameter larger than $10 \mu \mathrm{m}$ but the main part of graphite nodules have a size between 5 to $10 \mu \mathrm{m}$. Casting H4, $1.5 \mathrm{~mm}$ plate (Fig. 3 ) is one of the three cases while J4, $1.5 \mathrm{~mm}$ plate (Fig. 4) is not. The difference between these two is mainly the number of nodules in the intervals 5.0 to $7.5 \mu \mathrm{m}$ and 10.0 to $12.5 \mu \mathrm{m}$, see Figs. 3 and 4 .

In case of castings with many small nodules the FDM by Basak and Sengupta should be used in order to give the most reliable results. Otherwise Eq. (4) can give fast and reasonable results if the right $\alpha$ is used. Even if the fraction of graphite is lower than normal Eq. (4) gives good results as shown in Fig. 13.

The value of $\alpha=1.276$ is larger than the normal range from 1 to 1.25 [12] and it is also larger than the $\alpha=1.2$ used in [13]. However in the present case the larger $\alpha$ compensate for those graphite nodules having a visible cross section less than $d_{\text {limit, }}$, see Fig. 12.

It should be remembered that simple equations such as Eq. (4) only will give the total graphite nodule count. The FDM will in addition to that also give a 3D size distribution which is useful in defining the $d_{\text {limit }}$ or showing the number of primary nodules in hypereutectic castings. Furthermore can the size distribution also give some information about the tendency of formation of shrinkage porosities.

\subsubsection{Non-spherical nodules}

When converting the nodule count from 2D to 3D the equations are based on the assumption that all graphite nodules have a spherical shape. In case of degenerated graphite nodules as vermicular, chunky or exploded graphite none of the conversion method, neither the simple as e.g. Eq. (4) nor the more advanced as the FDM will give a reliable 3D nodule count. The problem of degenerated graphite nodules is however normally an issue for castings with low cooling rates and not for castings with high cooling rates as in thin walled castings [22, 27]. There are methods for treating spatial size distribution of non-spherical particles but the problem is complex and so are the conversion methods [17].

\section{Conclusion}

Graphite nodule count and size distribution have been analysed in thin walled ductile cast iron. The 2D nodule counts have been converted into 3D nodule count using a Finite Difference Method (FDM).

Particles having a diameter less than about $5 \mu \mathrm{m}$ should be neglected in the nodule count, as these mainly are inclusions or micro porosities. 
Neglecting particles smaller than a defined limit in the nodule count will affect the 2D nodule if there are many small nodules as in thin walled castings.

Simple equations such as Eq. (4) can give reliable results when converting 2D nodule count to 3D nodule count if the right value of $\alpha$ is used and if there only are few small nodules. The value of $\alpha$ can be evaluated by comparing with results from the FDM.

If there are many small graphite nodules only FDM will give reliable results. 2D nodule count or 3D nodule count based on simple equations will give too low results compared to thicker castings.

The use of simple equations when converting from 2D to 3D will only give the total nodule count. FDM will also give a 3D size distribution which can give information about shrinkage tendency.

In thin walled castings eutectic and hypereutectic castings have similar nodule count, while in heavy sections eutectic castings have lower nodule count than the hypereutectic castings.

\section{Acknowledgements}

This work has partly been financed by Technical University of Denmark and partly by the Danish Research Council for Technology and Production Sciences, which are greatly acknowledged.

\section{References}

[1] Skaland T, Grong Ø, Grong T. A model for the graphite formation in ductile cast iron. I. Inoculation mechanisms. Metall Trans A 1993;24A:2321-2345.

[2] Wetterfall S-E, Fredriksson H, Hillert M. Solidification process of nodular cast iron. Journal of The Iron and Steel Institute 1972;210:323-333.

[3] Tanaka Y, Yang Z, Miyamoto K. Evaluation of fatigue limit of spheroidal graphite cast iron. Mater Trans, JIM 1995;36:749-756.

[4] Labrecque C, Gagné M. Review: Ductile Iron: Fifty Years of Continuous Development. Canadian Metallurgical Quarterly 1998;37:343-378.

[5] Ruxanda RE, Stefanescu DM, Piwonka TS. Microstructure Characterization of Ductile Thin Wall Iron Castings. AFS Trans 2002;110:1131-1148.

[6] Basak CB, Sengupta AK. Development of a FDM based code to determine the 3-D size distribution of homogeneously dispersed spherical second phase from microstructure: A case study on nodular cast iron. Scripta Mater 2004;51:255260.

[7] Dogan ÖN, Schrems KK, Hawk JA. Microstructure of Thin-Wall Ductile Iron Castings. AFS Trans 2003;949-960. 
[8] Borrajo JM, Martinez RA, Sikora JA, Boeri RE. Shape and count of free graphite particles in thin wall ductile iron castings. ISIJ International 2002;42:257-263.

[9] Grum J, Sturm R. Analysis of graphite particles in different nodular irons obtained by the modified saltykov method.ITI'96 Proceedings of the 18th International Conference on Information Technology Interfaces. 1996, p. 261266.

[10] Lacaze J, Castro M, Lesoult G. Solidification of Spheroidal Graphite Cast Irons - II. Numerical Simulation. Acta Mater 1998;46:997-1010.

[11] Javaid A, Thomson J, Davis KG. Critical Conditions for Obtaining Carbide-Free Microstructure in Thin-Wall Ductile Irons. AFS Trans 2002;110:889-898.

[12] Owadano T. Graphite Nodule Number in Spheroidal Graphite and Malleable Cast Irons. Imono/Japan Foundrymen's Society 1973;45:193-197.

[13] Almansour A, Matsugi K, Hatayama T, Yanagisawa O. Simulating Solidification of Spheroidal Graphite Cast Iron of Fe-C-Si System. Mater Trans, JIM 1995;36:1487-1495.

[14] Charbon C. Modélisation Stochastique de la Solidification Eutectique Equiaxe, Ph.D. Thesis, École Polytechnique Fédérale de Lausanne, Lausanne, Switzerland; 1995.

[15] Wessén M, Svensson IL. Modeling of ferrite growth in nodular cast iron. Metall Mater Trans A 1996;27:2209-2220.

[16] Saltykov SA. Metallurg 1939;14:10-22.

[17] Underwood EE. Quantitative Stereology. Addison-Wesley Publishing Company; 1970, p. 109-145.

[18] Stefanescu DM, Qui HQ, Chen CH. Effects of selected metal and mold variables on dispersed shrinkage in SG cast iron. AFS Trans 1995;103:189-197.

[19] Underwood EE. Practical Solutions to Stereological Problems. In: McCall JL, Steele JHJr, editors. Practical Applications of Quantitative Metallography, ASTM STP 839.Philadelphia: American Society for Tesing and Materials; 1984, p. $160-179$.

[20] Jacobs MH, Law TJ, Melford DA, Stowell MJ. Basic processes controlling the nucleation of graphite nodules in chill cast iron. Metals Technology 1974;1:490500.

[21] Skaland T, Grong Ø, Grong T. A model for the graphite formation in ductile cast iron. II. Solid state transformation reactions. Metall Trans A 1993;24A:23472353. 
[22] Ductile Iron Handbook. Des Plaines, Illinois: American Foundrymen's Society, Inc.; 1992, p. 1-19 and 197-203.

[23] Bradley FJ. On the growth kinetics of primary graphite nodules in hypereutectic ductile iron. Scripta Metall Mater 1992;26:443-448.

[24] Sillén RV. Production of ductile iron castings without feeders. Foundry Trade Journal 2007;180:147-150.

[25] Skaland T. A new method for chill and shrinkage control in ladle treated ductile iron. The 66th World Foundry Congress, Istanbul, Turkey, September 6-9; 2004, p. $975-987$

[26] Kitsudou T, Okabe T, Fujita K, Nakayama Y. Effect of graphite morphology on shrinkage cavity formation of spheroidal graphite iron cast in metal mold. ISIJ International 1989;29:771-780.

[27] Källbom R, Hamberg K, Wessén M, Björkegren L-E. On the solidification sequence of ductile iron castings containing chunky graphite. Mater Sci Eng A 2005;413-414:346-351.

\section{Figures}
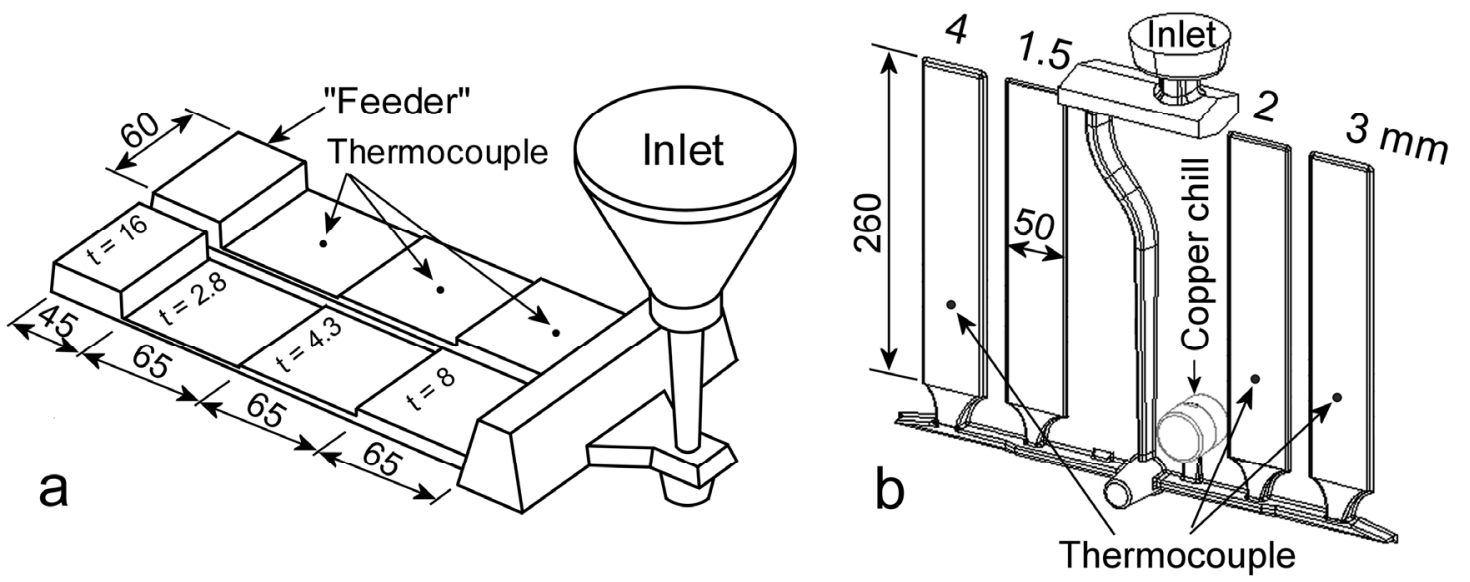

Fig. 1 Casting layout. a) Layout A, horizontal parted. b) Layout B, vertical parted 


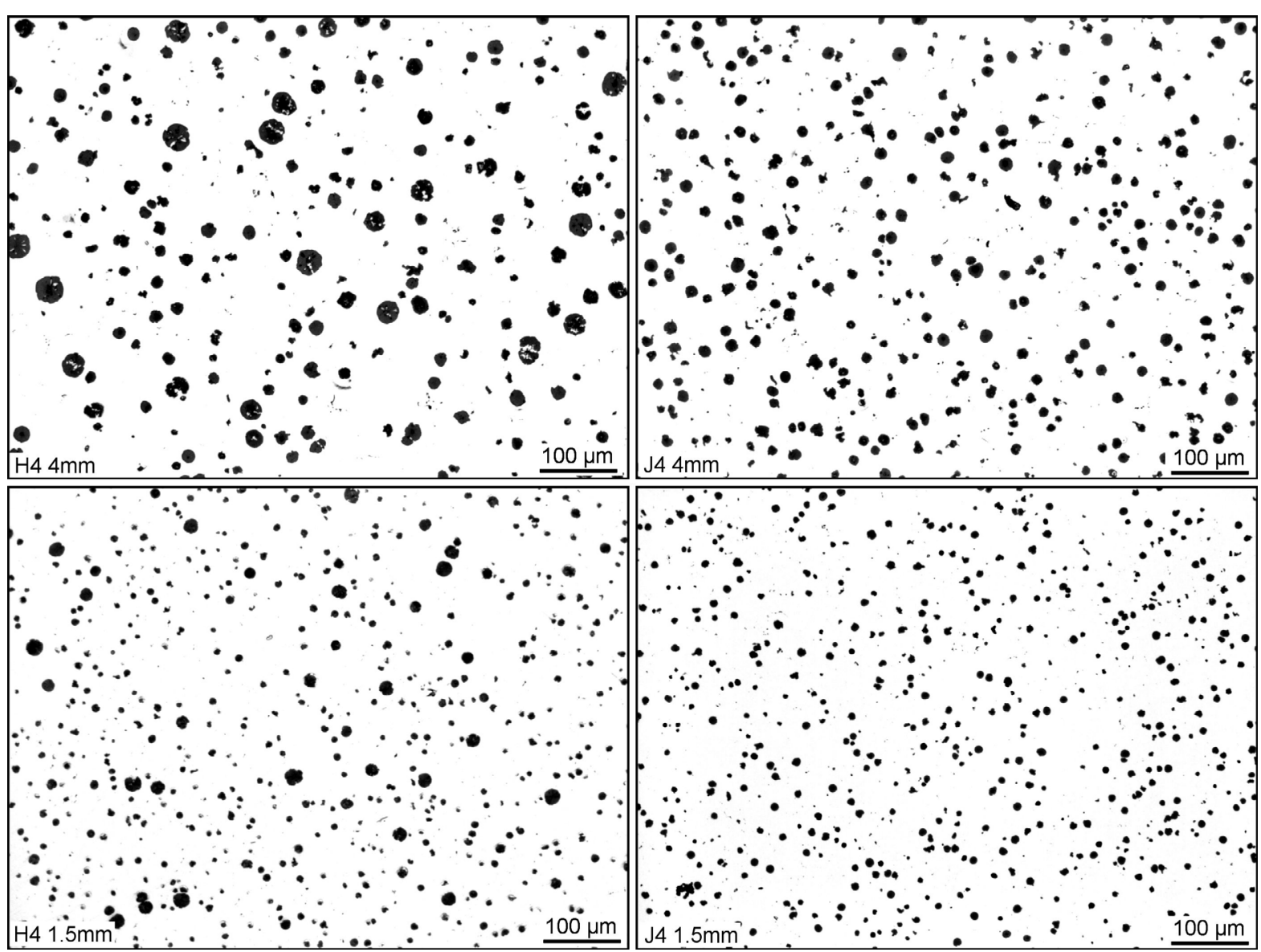

Fig. 2 Microstructure in a hypereutectic (H4) and a eutectic casting (J4) in the 4 and $1.5 \mathrm{~mm}$ plate (polished samples) 
Post-print of article in Materials Characterization 59 (2008) 1111-1121

Link to article: http://dx.doi.org/10.1016/j.matchar.2007.09.001
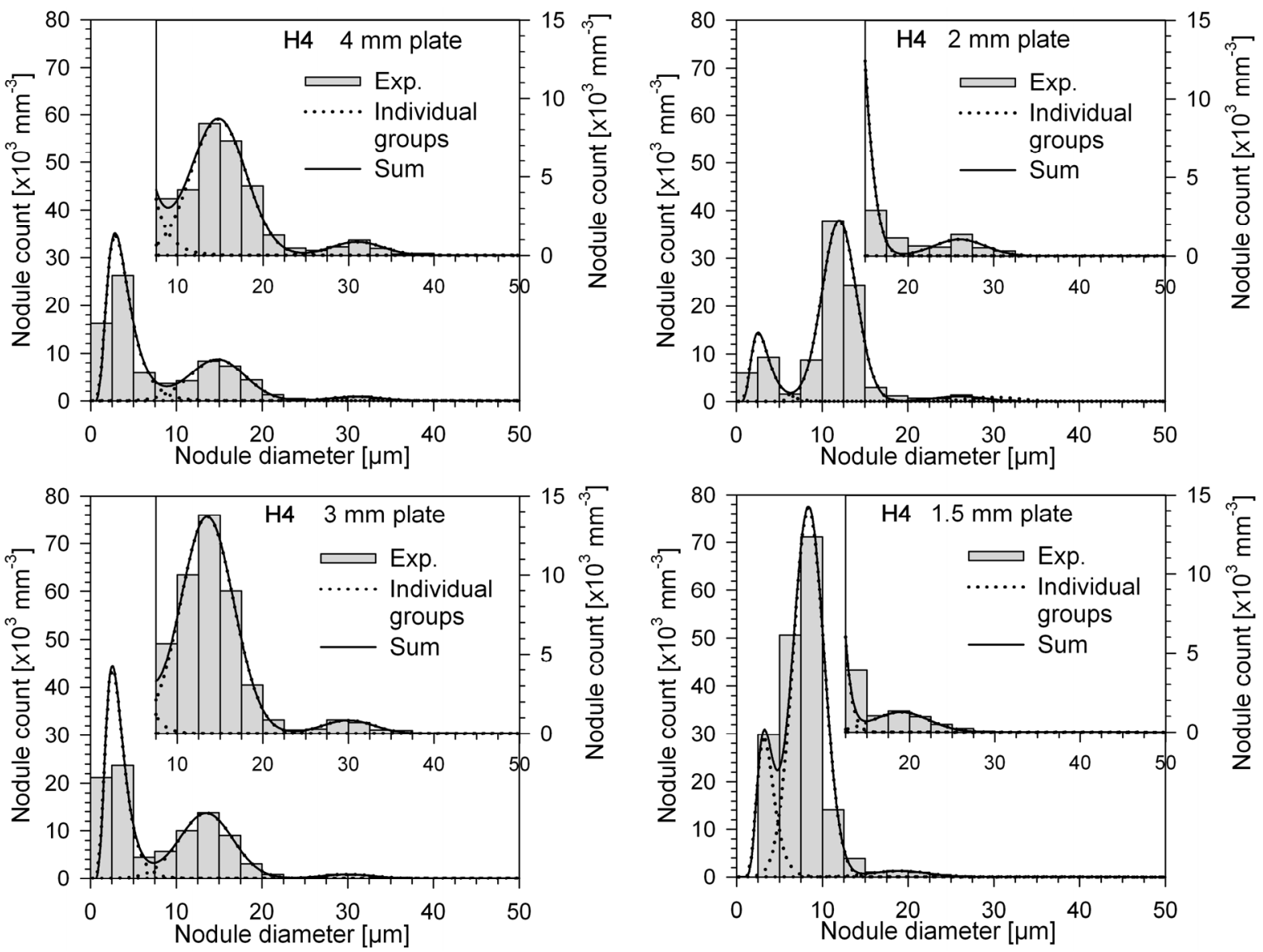

Fig. 3 Nodule size distribution for casting $\mathrm{H} 4$ (hypereutectic) for the four different plate thicknesses 

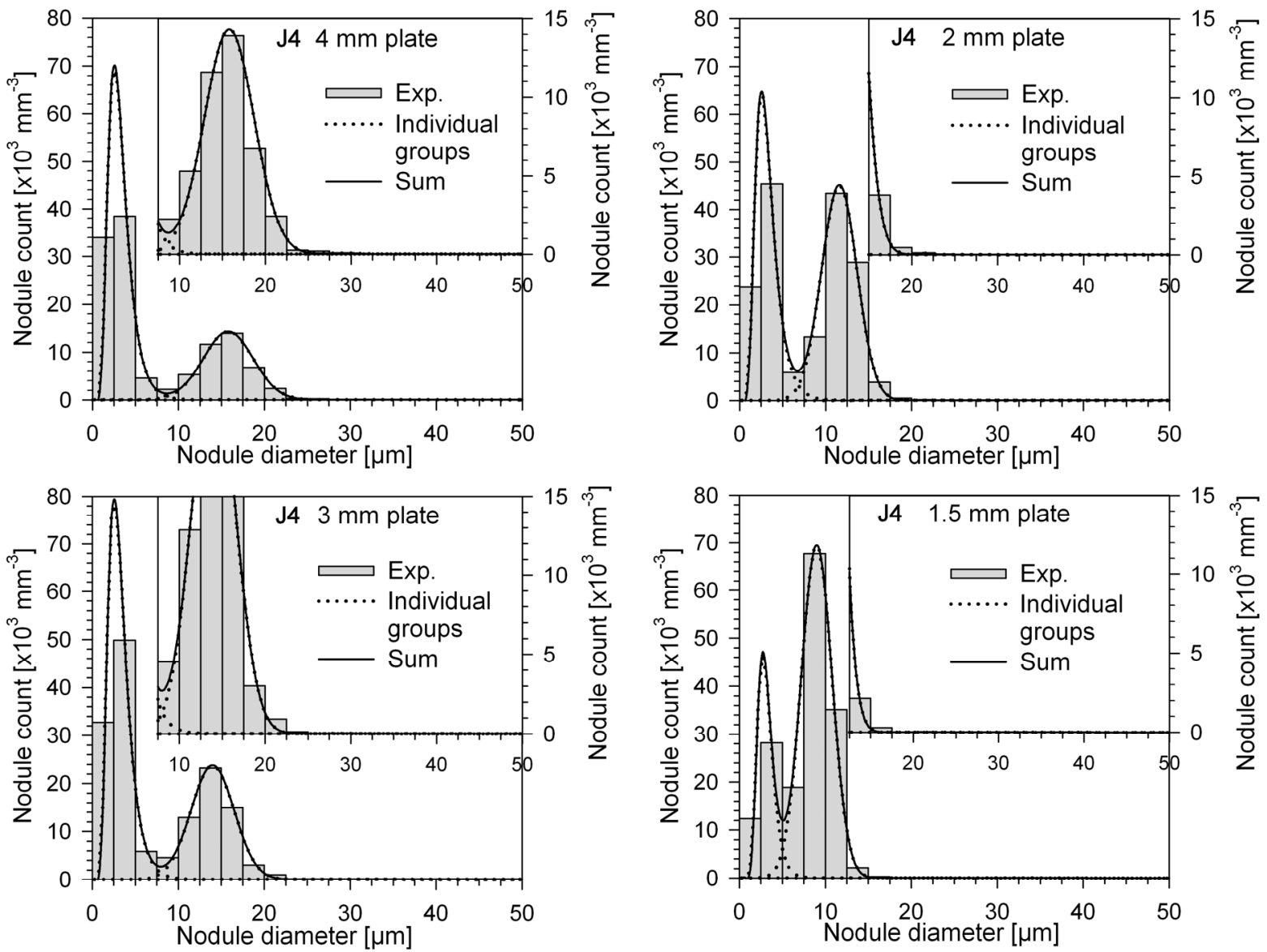

Fig. 4 Nodule size distribution for casting $\mathrm{J} 4$ (eutectic) for the four different plate thicknesses
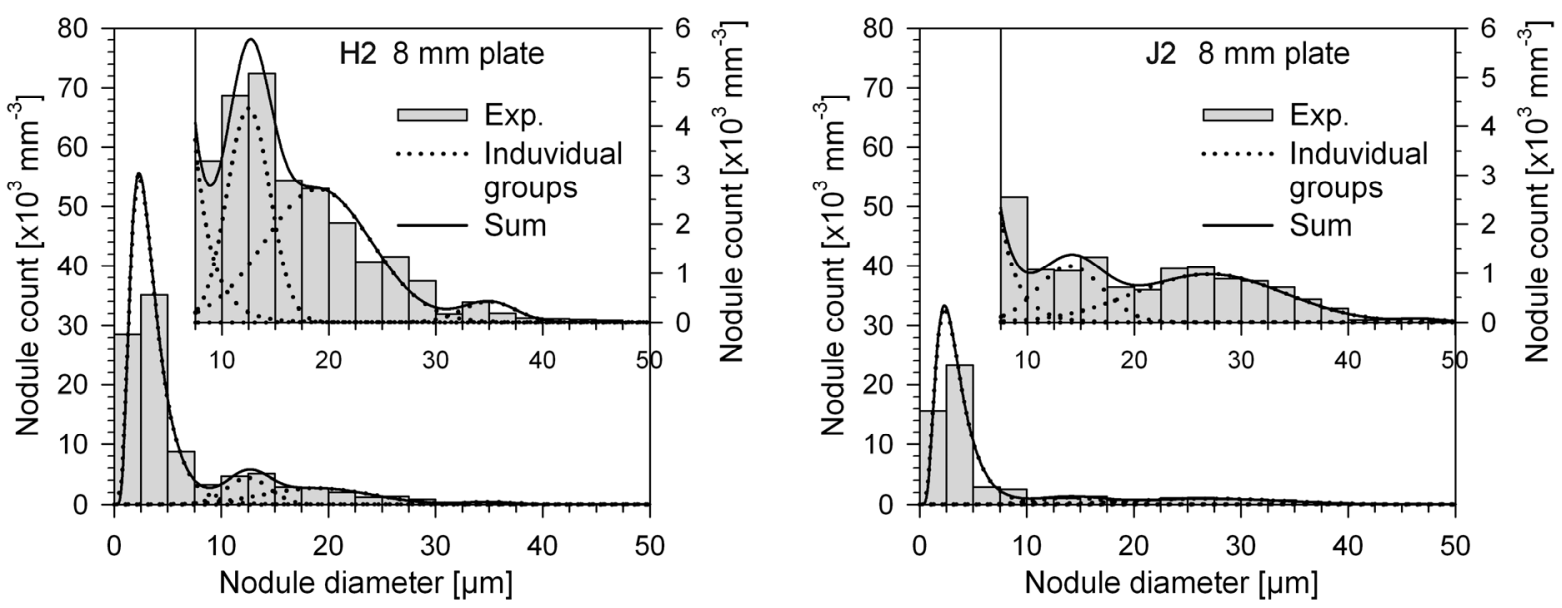

Fig. 5 Nodule size distribution for $8.0 \mathrm{~mm}$ plates for casting $\mathrm{H} 2$ (hypereutectic) and $\mathrm{J} 2$ (eutectic) 


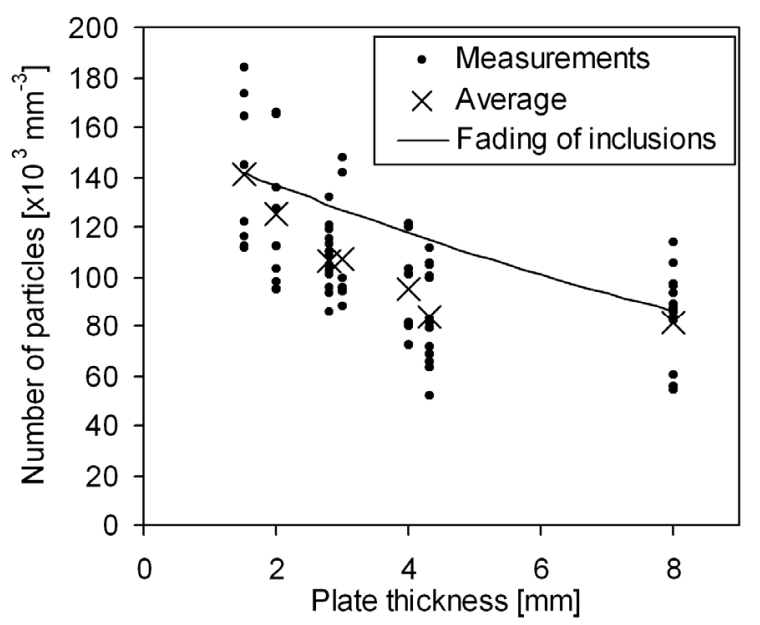

Fig. 6 Total number of detectable particles (sum of inclusions, micro porosities and graphite nodules) in the castings

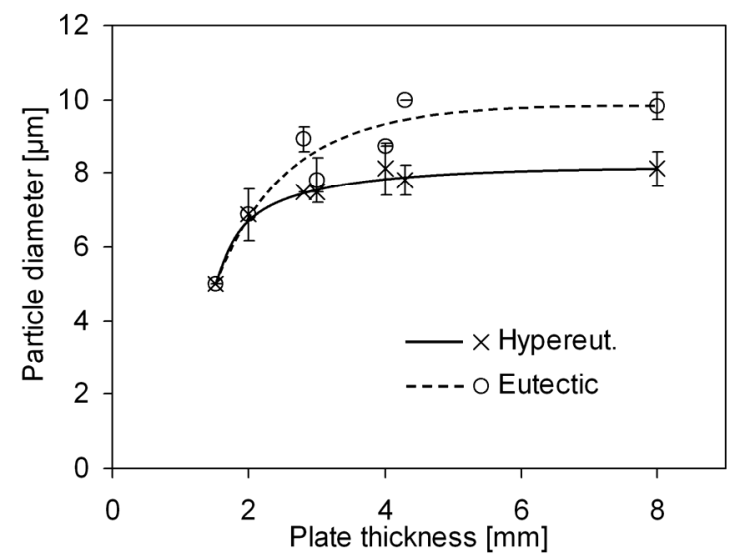

Fig. 7 Size limit between small particles / micro porosities and graphite nodules. Particles smaller than the size limit are neglected in the nodule count.

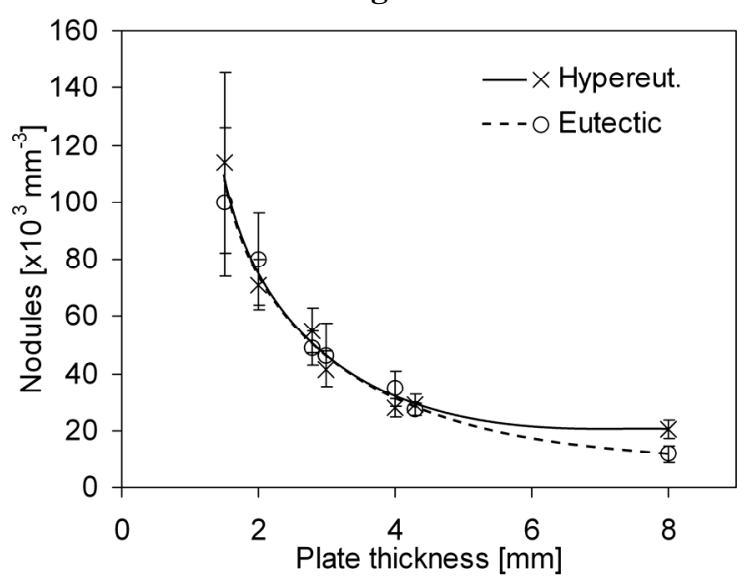

Fig. 8 Average nodule count 


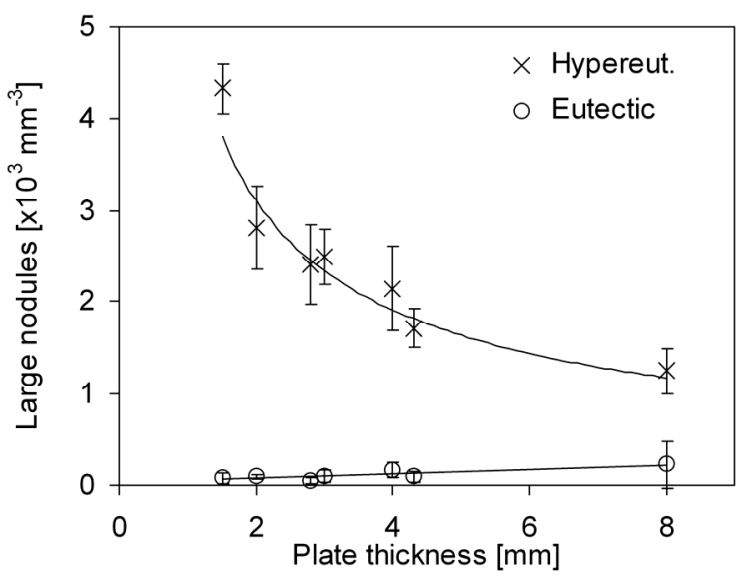

Fig. 9 Average number of large nodules in hypereutectic and eutectic castings
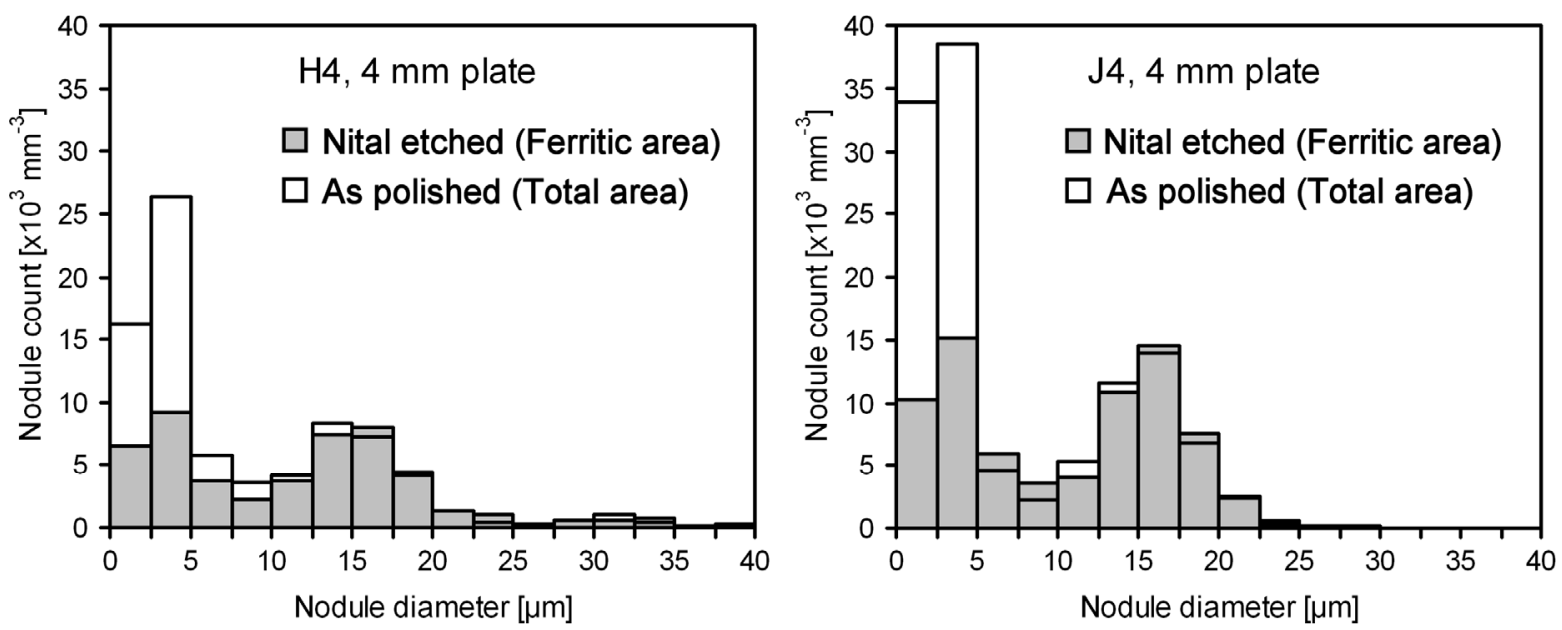

Fig. 10 Nodule count on a 'As polished' sample and nodule count in ferritic areas on a Nital etched sample for a hypereutectic casting (H4) and eutectic casting (J4)

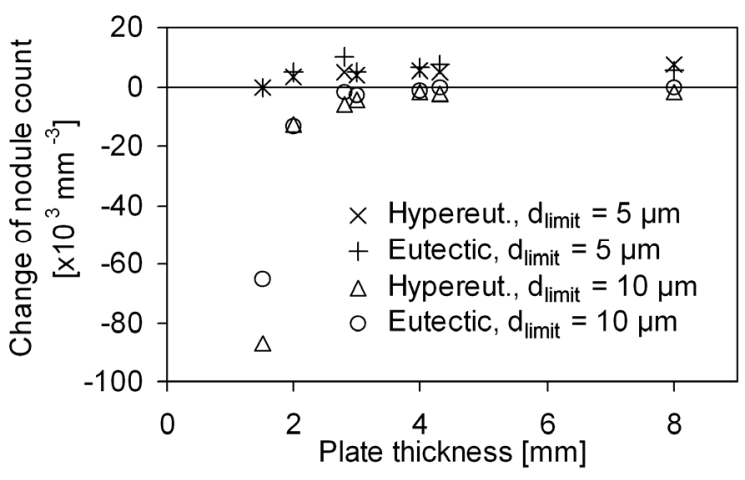

Fig. 11 Average change in nodule count if the minimum size limit of the diameter is 5 or $10 \mu \mathrm{m}$ 
Post-print of article in Materials Characterization 59 (2008) 1111-1121

Link to article: http://dx.doi.org/10.1016/j.matchar.2007.09.001

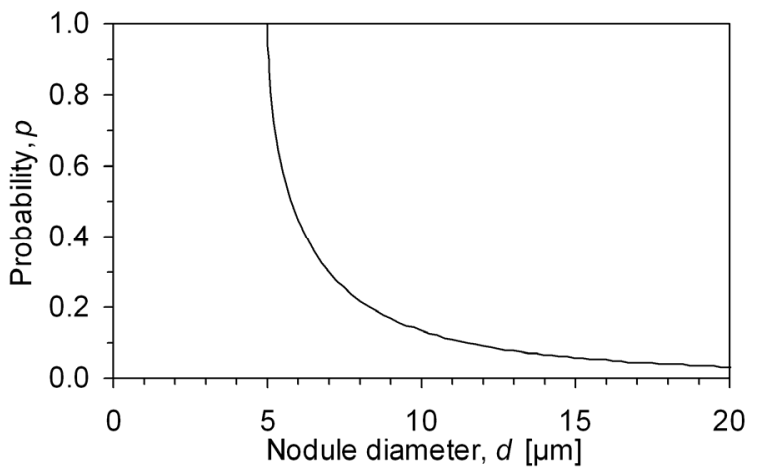

Fig. 12 Probability that a nodule with diameter $d$ has a visible diameter less than $d_{\text {limit }}=5 \mu \mathrm{m}$

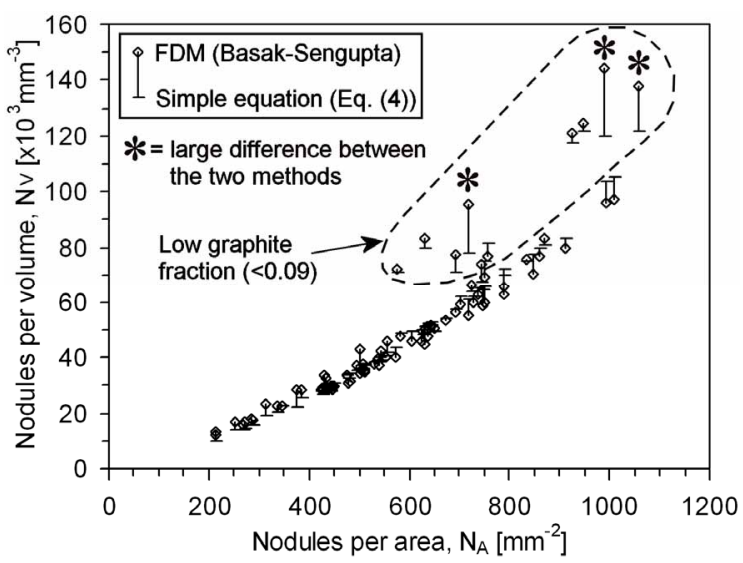

Fig. 13 Difference between 3D count calculated by the FDM of Basak and Sengupta or by Eq. (4) taking $f^{g}$ into account and $\alpha=1.276$

\section{Tables}

Table 1 Chemical analysis of castings $(\mathrm{CEV}=\% \mathrm{C}+0.28 \times \% \mathrm{Si})$ and casting temperature

\begin{tabular}{|c|c|c|c|c|c|c|c|c|c|}
\hline \multicolumn{2}{|c|}{ Experiment } & $\mathrm{C}$ & $\mathrm{Si}$ & $\mathrm{Mn}$ & $\mathrm{P}$ & $S$ & $\mathrm{Mg}$ & CEV & $\begin{array}{c}\text { Casting } \\
\text { Temp. }\left[{ }^{\circ} \mathrm{C}\right]\end{array}$ \\
\hline \multirow[t]{3}{*}{ Hypereutectic } & $\mathrm{E}$ & 3.70 & 2.75 & 0.044 & 0.025 & 0.010 & 0.037 & 4.47 & 1340 \\
\hline & $\mathrm{H}$ & 3.90 & 2.69 & 0.045 & 0.021 & 0.010 & 0.033 & 4.65 & 1370 \\
\hline & K & 4.15 & 2.11 & 0.040 & 0.024 & 0.013 & 0.039 & 4.74 & 1360 \\
\hline \multirow[t]{3}{*}{$\overline{\text { Eutectic }}$} & $\mathrm{F}$ & 3.51 & 2.70 & 0.044 & 0.026 & 0.010 & 0.030 & 4.27 & 1350 \\
\hline & $\mathrm{J}$ & 3.57 & 2.64 & 0.041 & 0.022 & 0.011 & 0.028 & 4.31 & 1350 \\
\hline & $\mathrm{L}$ & 3.65 & 2.10 & 0.042 & 0.025 & 0.013 & 0.038 & 4.24 & 1350 \\
\hline
\end{tabular}

For all castings: Ni 0.017; Cr 0.032; Al 0.01; Co 0.025; Cu 0.007; Ti 0.02; $\mathrm{V} 0.03$; $\mathrm{W}<0.007$; Mo, Nb, As, Sn and $\mathrm{Pb}<0.005$; Zr, Zn and $\mathrm{B}<0.001$ 
Post-print of article in Materials Characterization 59 (2008) 1111-1121

Link to article: http://dx.doi.org/10.1016/j.matchar.2007.09.001

Table 2 The used casting layout for the different experiments

\begin{tabular}{lccc}
\hline \multirow{2}{*}{ Experiments } & & \multicolumn{2}{c}{ Moulds } \\
\cline { 3 - 4 } Hypereutectic & $\mathrm{E}$ & Casting layout A & Casting layout B \\
& $\mathrm{H}$ & $\mathrm{H} 1, \mathrm{H} 2$ & - \\
& $\mathrm{K}$ & $\mathrm{K} 1, \mathrm{~K} 2$ & $\mathrm{H} 3, \mathrm{H} 4$ \\
& $\mathrm{~F}$ & $\mathrm{~F} 3, \mathrm{~F} 4, \mathrm{~F} 5$ & $\mathrm{~K} 3, \mathrm{~K} 4$ \\
\hline Eutectic & $\mathrm{J}$ & $\mathrm{J} 1, \mathrm{~J} 2$ & - \\
& $\mathrm{L}$ & $\mathrm{L} 1, \mathrm{~L} 2$ & $\mathrm{~J} 3, \mathrm{~J} 4$ \\
& & & $\mathrm{~L} 3, \mathrm{~L} 4$ \\
\hline
\end{tabular}

